\title{
The pulmonary endothelium in acute respiratory distress syndrome: insights and therapeutic opportunities
}

\author{
Fraser R Millar, ${ }^{1}$ Charlotte Summers, ${ }^{2,3}$ Mark J Griffiths, ${ }^{1,4}$ Mark R Toshner, ${ }^{3}$ \\ Alastair G Proudfoot ${ }^{1,5}$
}

${ }^{1}$ Leukocyte Biology Section, National Heart \& Lung Institute, Imperial College, London, UK

${ }^{2}$ Division of Anaesthesia, Department of Medicine, University of Cambridge, Cambridge, UK ${ }^{3}$ Papworth Hospital NHS Foundation Trust, Cambridge, UK

${ }^{4} \mathrm{NIHR}$ Respiratory Biomedical Research Unit, Royal Brompton \& Harefield Hospital, NHS Foundation Trust, London, UK ${ }^{5}$ Frederick Meijer Heart \& Vascular Institute, Spectrum Health, Grand Rapids, Michigan, USA

\section{Correspondence to} Dr Alastair Proudfoot, Frederick Meijer Heart \& Vascular Institute, Spectrum Health, 100 Michigan Street NE, Grand Rapids, MI 49503, USA; Alastair.Proudfoot@ spectrumhealth.org

Received 19 June 2015 Revised 9 February 2016 Accepted 12 February 2016 Published Online First 11 March 2016

\section{ABSTRACT}

The pulmonary endothelium is a dynamic, metabolically active layer of squamous endothelial cells ideally placed to mediate key processes involved in lung homoeostasis. Many of these are disrupted in acute respiratory distress syndrome (ARDS), a syndrome with appreciable mortality and no effective pharmacotherapy. In this review, we consider the role of the pulmonary endothelium as a key modulator and orchestrator of ARDS, highlighting advances in our understanding of endothelial pathobiology and their implications for the development of endothelial-targeted therapeutics including cell-based therapies. We also discuss mechanisms to facilitate the translation of preclinical data into effective therapies including the application of biomarkers to phenotype patients with ARDS with a predominance of endothelial injury and emerging biotechnologies that could enhance delivery, discovery and testing of lung endothelial-specific therapeutics.

\section{INTRODUCTION}

The pulmonary vasculature is a homogenous layer of squamous endothelial cells lining the entire pulmonary circulation. Having initially been thought of as an inert, static structure, the lung endothelium is increasingly recognised as a dynamic, metabolically active organ that modulates several key regulatory functions including: leucocyte diapedesis, intravascular coagulation, vasomotor tone, and solute and fluid trafficking via regulation of barrier permeability.

The pulmonary endothelium is distinct from the systemic vascular bed, in that it is exposed to the highest oxygen tension, while maintaining low-pressure blood flow. Coupled with the lung possessing the highest abundance of endothelial cells relative to the total cell population and its vast surface area, it is ideally placed to interact with bloodborne cells and vasoactive mediators to sense mechanical, chemical and cellular stimuli. While this allows the endothelium to regulate local (and possibly systemic) inflammation, disruption of lung endothelial homoeostatic mechanisms transforms it from a primarily anti-inflammatory phenotype to an activated proinflammatory phenotype that propagates lung parenchymal inflammation. ${ }^{1}$

Disruption of lung endothelial homoeostasis manifests clinically as acute respiratory distress syndrome (ARDS). ARDS is characterised by acute inflammation of the gas exchange surface of the lung. Dysregulated inflammation promotes the pulmonary accumulation of leucocytes and platelets, while activation of procoagulant pathways and disruption of alveolar capillary membrane barrier function leads to hypoxia, hypercapnoea and pulmonary oedema. Thus, ARDS presents clinically with acute onset of breathlessness and hypoxaemia in the presence of diffuse pulmonary oedema on the chest radiograph, with the majority of patients requiring mechanical ventilation. Risk factors for ARDS can be divided into two groups, depending on whether injury to the lung is direct such as pneumonia, with predominantly epithelial injury, or indirect bloodborne insults, such as severe sepsis, with a predominance of endothelial injury (table 1). Although mortality in ARDS has temporally declined, it remains between $25 \%$ and $35 \%{ }^{2}$ and there is currently no licensed effective pharmacotherapy, highlighting the need for novel therapeutic strategies. Contemporary management focuses on treatment of the underlying cause and organ support while avoiding iatrogenic injury, most notably with low tidal volume and pressure mechanical ventilation and a conservative fluid management strategy. ${ }^{3}$

In this article we focus on our current understanding of the role of the pulmonary endothelium in orchestrating and propagating ARDS, and further explore the endothelium as an emerging pharmacological target in ARDS. It is important to note that the pulmonary endothelium is structurally, morphologically and functionally distinct from the systemic vasculature (reviewed in refs. 4 5). Accordingly, this review will address data generated in relevant models of pulmonary endothelial injury, with reference to recent specific expert reviews where appropriate.

\section{STRUCTURE AND FUNCTION OF THE PULMONARY ENDOTHELIUM}

The pulmonary endothelium forms a single layer of mesenchyme-derived and non-fenestrated endothelial cells. This serves as a semipermeable barrier separating the pulmonary circulation from the lung interstitium, regulating macromolecule, nutrient, leucocyte and fluid transfer.

The integrity of this barrier is determined by homophilic interactions between neighbouring endothelial cells via intercellular junctions (tight junctions and adherens junctions (AJs); reviewed in ref. 6). These junctions link endothelial cells and are served by cytoskeletal microtubules and actin microfilaments to facilitate both maintenance of barrier function and modulation of signal transduction in response to the tethering and contractile 
Table 1 Indirect and direct ARDS—distinguishing features

\begin{tabular}{|c|c|c|}
\hline & Indirect ARDS & Direct ARDS \\
\hline Causes & $\begin{array}{l}\text { Severe sepsis } \\
\text { Trauma } \\
\text { Blood product transfusion (TRALI) } \\
\text { Pancreatitis } \\
\text { Cardiopulmonary bypass } \\
\text { Burns }\end{array}$ & $\begin{array}{l}\text { Pneumonia } \\
\text { Aspiration } \\
\text { Smoke inhalation } \\
\text { Pulmonary contusion } \\
\text { Reperfusion injury }\end{array}$ \\
\hline $\begin{array}{l}\text { Clinicopathological } \\
\text { hallmarks }\end{array}$ & $\begin{array}{l}\text { Neutrophilic alveolitis } \\
\text { Hyaline membranes } \\
\text { Microthrombi } \\
\text { Probable predominance of endothelial injury } \\
\text { Imaging and plasma evidence of (non-pulmonary) pathology, } \\
\text { for example, pancreatitis }\end{array}$ & $\begin{array}{l}\text { Neutrophilic alveolitis } \\
\text { Hyaline membranes } \\
\text { Microthrombi } \\
\text { Probable predominance of alveolar epithelial injury } \\
\text { Chest imaging evidence (CT) of initiating process, for example, } \\
\text { lung contusion }\end{array}$ \\
\hline Proposed biomarkers & $\begin{array}{l}\text { Angiopoetin-2 } \\
\text { von Willebrand factor } \\
\text { Soluble thrombomodulin } \\
\text { Interleukin } 8 \\
\text { Soluble ICAM-1 }\end{array}$ & $\begin{array}{l}\text { Surfactant protein-D } \\
\text { Receptor for advanced glycation end products } \\
\text { Krebs von den Lungen- } 6 \\
\text { Club cell } 16\end{array}$ \\
\hline
\end{tabular}

forces exerted on the endothelium during mechanical ventilation. $^{7}$

Tight junctions are formed by the fusion of the outer layers of the plasma membranes and are comprised of occludins, claudins and junctional adhesion molecules coupled to cytoplasmic proteins and linked to the endothelial cell actin cytoskeleton by the zonula occludens family. AJs are composed of cadherins, primarily vascular endothelial cadherin (VE-cadherin), that bind intracellular catenin proteins (including p120-catenin, a VE-cadherin stabilising protein) that in turn bind to other protein partners in the actin cytoskeleton. AJs are mediated by calcium-dependent association of cadherin proteins and regulate the paracellular transport (the predominant pathway) of cells and solutes between the blood and the interstitium. Hence AJs, and specifically VE-cadherin, are key regulators of paracellular permeability, which determines leucocyte transmigration and oedema formation ${ }^{8}$ while cell membrane scaffolding proteins called caveolins regulate transendothelial trafficking (transcytosis) of macromolecules including albumin. ${ }^{9}{ }^{10}$ Data suggest that transcellular permeability increases may precede and subsequently trigger paracellular permeability via Src-mediated phosphorylation of caveolin-1. ${ }^{10}$ Endothelial cells are tethered to the extracellular matrix (ECM) via interaction between cell surface integrins and their ECM ligands, which are organised in focal adhesion plaques. $^{11}$

A negatively charged extracellular layer of proteoglycans, glycoproteins and glycosaminoglycans (GAGs) that line intimal surfaces, the endothelial glycocalyx, may act as an additional barrier to large molecules and circulating cells. Data from a murine ARDS model suggested that the glycocalyx-modulated neutrophil diapedesis via heparinase-mediated glycocalyx shedding and consequent exposure of neutrophil adhesion molecules, ${ }^{12}$ while in vitro human data proposed that the sialic acid component of the glycocalyx maintained barrier function via regulation of cell-matrix and cell-cell interactions. ${ }^{13}$ Despite these and other observations (reviewed in ref. 14), it remains unclear whether and how the glycocalyx contributes to the pathogenesis of human ARDS.

The endothelium performs additional regulatory roles in gas exchange, vascular tone and coagulation (reviewed in ref. 15). As an integral component of the alveolar-capillary unit, it is structurally and functionally optimised to facilitate perfusion- ventilation matching. Hence, lung endothelial cells regulate the synthesis and metabolism of vasoactive compounds such as nitric oxide and endothelin-1, potent regulators of pulmonary vascular tone. Furthermore, the endothelium also produces both prothrombic and antithrombotic substances which act both locally and remotely to regulate coagulation. It separates bloodborne cellular (eg, platelets) and humoral (eg, coagulation factors) components of the coagulation cascade from prothrombotic substances in the lung interstitium and alveolar space.

\section{PULMONARY ENDOTHELIAL ACTIVATION IN ARDS Pathobiology}

In health, the lung endothelium adopts a predominantly inhibitory effect on inflammation and coagulation. However, upon 'activation' by a range of stimuli including hypoxia, cytokines (eg, tumour necrosis factor $\alpha$ (TNF) and interleukin (IL) 1ß), chemokines (eg, IL-8), thrombin and bacterial endotoxins, including lipopolysaccharide (LPS) and interactions with activated inflammatory cells, a shift towards a proinflammatory phenotype occurs. ${ }^{1}$ Indeed, dysregulated endothelial activation and the resultant loss of homoeostatic mechanisms are aspects of ARDS pathobiology that may distinguish it from self-limiting, localised insults, for example bacterial pneumonia. ${ }^{1}$

Accordingly, lung endothelial cells are increasingly recognised as orchestrators of the inflammatory response. In experimental influenza models, the pulmonary endothelium was a key regulator of innate cellular and cytokine responses, if not the actual source of cytokine release. ${ }^{16}$ In addition, endothelial cells express various leucocyte adhesion molecules including intracellular adhesion molecule-1 (ICAM-1), vascular cell adhesion molecule-1 (VCAM-1) and E-selectin. ${ }^{17}$ These proinflammatory responses may exhibit calcium dependency; TNF and IL-8 release from lung microvascular endothelial cells stimulated with LPS correlated with an increase in intracellular calcium, ${ }^{18}$ while cytosolic calcium oscillations induced proinflammatory gene transcription and endothelial E-selectin expression. ${ }^{19}$ Reactive oxygen species (ROS) and reactive nitrogen species production by activated cells saturate local antioxidants and contribute to tissue injury directly via downregulation of VE-cadherin, ${ }^{20}$ upregulation of neutrophil adhesion molecule expression and release of neutrophil chemotactic factors. ${ }^{21}$ 
Activated endothelial cells also assume a procoagulant phenotype to limit damage to lung microvasculature and localise infection. This is characterised by increased expression of platelet adhesion molecules, intra-alveolar and intravascular fibrin deposition, and release of activators of the extrinsic coagulation cascade, ${ }^{22}$ in particular nitric oxide. ${ }^{23}$ Moreover, upregulation and activation of tissue factor and loss of the ability to activate protein $\mathrm{C}$ and $\mathrm{S}$ results in capillary thrombosis and extravascular fibrin deposition, thereby contributing to the increased dead-space fraction that correlates with clinical outcomes. $^{24}$

\section{Clinical and therapeutic significance}

While potentially propagating injury, the expression and release of proinflammatory molecules has driven research first into using these molecules as biomarkers of ARDS and second as putative pharmacological targets. Moreover, there is increasing evidence that the alveolar and vascular compartments are biologically distinct despite the alveolar capillary membrane disruption seen in ARDS supporting the notion that 'phenotypical signatures' identifying patients with site-predominant injury (endothelial vs epithelial) could be generated.

Angiopoetin-2 (Ang-2) is an endothelial growth factor, produced by endothelial cells, that regulates vascular permeability, promoting cell death and vascular regression. An incremental rise in plasma Ang-2, suggestive of progressive endothelial injury $^{25}$ predicted mortality in patients with sepsis-related ARDS. ${ }^{26}$ Similarly, higher circulating GAG levels (reflecting the integrity of the glycocalyx) were found in those patients with non-pulmonary insults (ie, patients with indirect ARDS) although these did not predict outcome. ${ }^{27}$ In other studies, plasma levels of soluble thrombomodulin (TM), ${ }^{28}$ the circulating form of a transmembrane endothelial glycoprotein with antithrombotic and anti-inflammatory capabilities, and von Willebrand factor (vWF), ${ }^{29}$ a glycoprotein produced by endothelial cells, predicted mortality in ARDS. Finally, endothelialderived microparticles (EMPs), submicron vesicles formed during membrane blebbing that shuttle proteins, organelles, lipids and RNA are an emerging biomarker of lung endothelial activation (reviewed in ref. 30), particularly in the context of mechanical stretch. Hence, EMP levels were elevated in human macrovascular endothelial cells and animals exposed to pathological mechanical stress as well as endotoxin. ${ }^{31} 32$

Using unbiased latent class analysis, a recent study identified two distinct cohorts of patients with ARDS who differed predominantly in their inflammatory profile and more significantly divergent responses to the application of different ventilator strategies. ${ }^{33}$ While this study did not differentiate endothelial injury from epithelial injury, it suggests that patient endotyping may hold value in predicting response to therapy. Coupled with evidence from biomarker studies outlined above, it is becoming increasingly plausible that researchers may soon be able to enrol subphenotypes of patients with ARDS with a predominance of endothelial injury to enrich enrolment in trials, thus optimising trial design and potential outcomes.

The expression of cell surface receptors and adhesion molecules also provides a putative platform to apply advances in pulmonary endothelial immunotargeting. Coupled with advanced drug delivery systems (such as liposomes, nanocarriers and host carriers) this methodology may facilitate targeting of specific aspects of lung endothelial injury in ARDS. For example, antioxidants conjugated with antibodies to the endothelial determinant Platelet/Endothelial Cell Adhesion Molecule 1 (PECAM-1) inhibited endothelial activation and reduced
VCAM-1 expression in murine lung injury. ${ }^{34}$ Similarly, dexamethasone-loaded nanogels targeted to ICAM-1 accumulated in murine LPS-injured lungs and blocked expression of ICAM-1 and VCAM-1 at $24 \mathrm{~h}^{35}$ In an effort to both target the lung endothelium and enhance biological effect, researchers have fused single-chain fragments of PECAM-1 antibodies to recombinant TM and endothelial protein $C$ receptor (EPCR). Using this dual-targeting approach, a fivefold increase in receptor activation compared with isolated TM or EPCR targeting was observed as well as amelioration of lung injury parameters. ${ }^{36}$ Translation of these methods to clinical use will be challenging and costs may be prohibitive; nonetheless, these novel methods of targeted drug delivery hold promise.

\section{MECHANISMS OF ENDOTHELIAL BARRIER DISRUPTION AND INJURY IN ARDS}

Loss of barrier integrity, characterised by the formation of reversible intercellular gaps between endothelial cells, is accepted as the ultrastructural basis for the increased permeability pulmonary oedema observed in ARDS. ${ }^{37}$ A range of circulating (TNF, IL-6, LPS), released (ROS, histamine) and physical (mechanical stretch) effectors disrupt the endothelial barrier, principally by causing activation of the actin-myosin contractile apparatus which causes dispersion of cortical actin filaments and increased prominence of stress fibres which extend throughout the cytoplasm. Actinomyosin contraction of these stress fibres increases tension and is proposed to cause cell contraction, pulling cells apart and compromising barrier integrity. ${ }^{7}$ Contractile machinery is regulated by the phosphorylation status of the critical actin binding protein, myosin light chain (MLC) on Ser-19 or Ser-19/Thr-18. This is controlled through an interplay of the calcium/calmodulin-dependent MLC kinase (MLCK, phosphorylation) and Rho-regulated MLC phosphatase (MLCP, dephosphorylation). ${ }^{38}$ Hence, MLCK in particular, plays an essential role in both barrier disruption and restoration in an agonist-specific manner ${ }^{39-41}$ (figure 1).

Although data specific to the lung endothelium is comparatively limited, regulatory small GTPases including RhoA, Rac1, cell division control protein $42(\mathrm{Cdc} 42)$ and Rap1 are central intracellular regulators of the actin cytoskeleton and thus barrier function. Broadly, Rho negatively regulates barrier function ${ }^{42}$ and Cdc42 and Rap1 signalling enhance barrier function. ${ }^{43} 44$ RhoA through its regulated signalling circuitry, including the serine-threonine Rho-associated protein kinase (ROCK), induces phosphorylation of MLC (via MLCK) as well as inhibition of MLCP, inducing cytoskeletal remodelling and barrier permeability. ${ }^{45-47} \mathrm{Cdc} 42$ directly regulates cortical actin organisation as well as a host of proteins including cofilin, MLCK and neural-Wiskott Aldrich syndrome protein that affect actin organisation and cell adhesion to the ECM. ${ }^{44}$ Ras-related C3 botulinum toxin substrate 1 (Rac1) can either positively or negatively regulate barrier function in a stimulus-dependent manner, ${ }^{48-50}$ while Rap1 enhances barrier function via inhibition of Rho and activation of $\mathrm{Cdc} 42^{51} 52$ as well as a cooperative association with VE-cadherin. ${ }^{53}$

Other intracellular mediators include cyclic AMP (cAMP), nuclear factor $\kappa \mathrm{B}(\mathrm{NF}-\kappa \mathrm{B})$ and focal adhesion kinase (FAK). An increase in cAMP levels in response to a range of mediators reduces vascular leakage through activation of protein kinase $\mathrm{A}$ (PKA) and the guanine exchange factor, exchange protein activated by cAMP (Epac). ${ }^{54}$ PKA inhibits RhoA activation and endothelial cell (EC) contraction ${ }^{56}$ and Epac (via Rap1) enhances VE-cadherin junctional integrity and actin reorganisation. ${ }^{53}$ FAK, a non-receptor tyrosine kinase regulates turnover 
Barrier Disruption

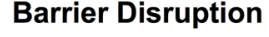

\section{Barrier Enhancement}

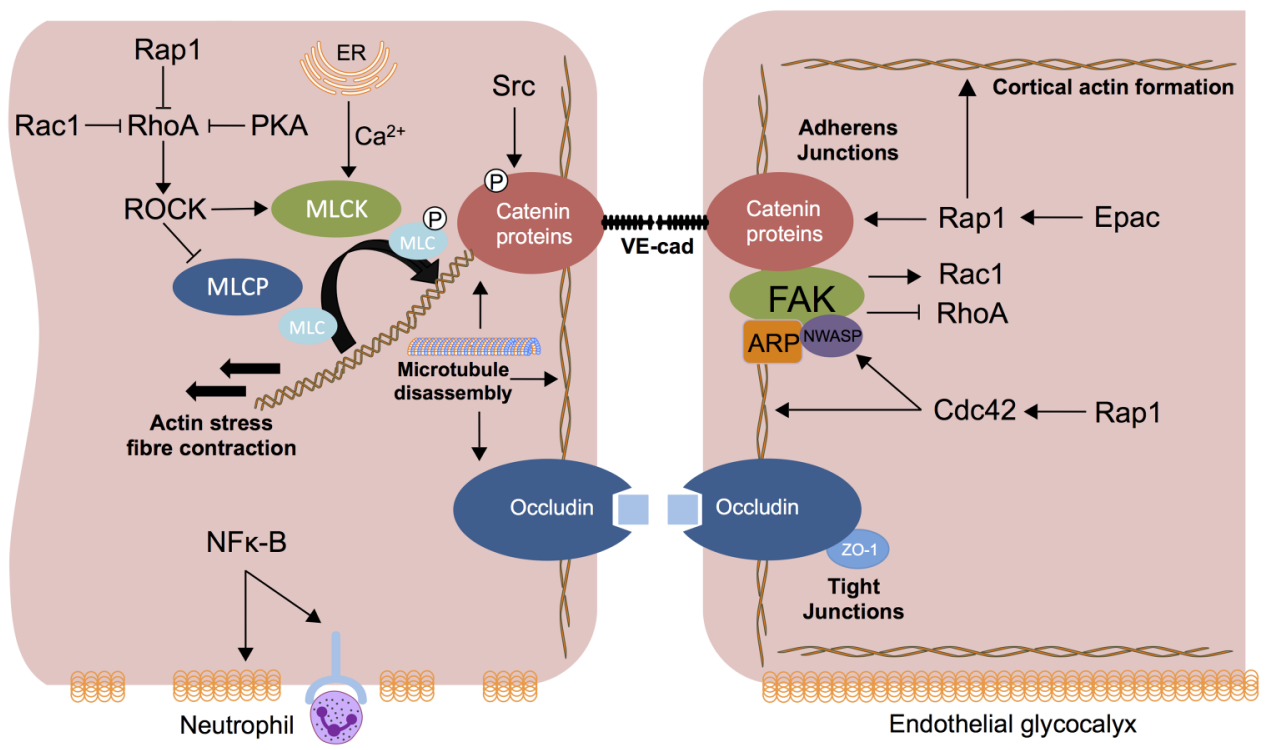

Figure 1 Mechanisms of pulmonary endothelial barrier disruption and enhancement. Barrier disruption results from actin-myosin interaction after MLC-phosphorylation, which is regulated by myosin light chain kinase (MLCK) and myosin light chain phosphatase (MLCP). Activation of the actin myosin contractile apparatus disperses cortical actin and increases actin stress fibre formation, resulting in cell contraction and tensional force applied to adherens junction (AJ) proteins. RhoA acts via effector protein Rho-associated protein kinase (ROCK) to activate MLCK and inhibit MLCP. RhoA activity is inhibited by the GTPases Rap1 and Rac1 as well as cyclic AMP (cAMP) induced protein kinase A (PKA) activation. MLCK activation is modulated by $\mathrm{Ca}^{2+}$ which enters the cytosol from endoplasmic reticulum (ER) or extracellular space. Phosphorylation of specific tyrosine residues of cytoskeletal proteins and adhesion molecules including vascular endothelial cadherin (VE-cadherin) as well as microtubule disassembly are MLCK-independent mechanisms of barrier disruption; Src mediated VE-cadherin phosphorylation leads to VE-cadherin internalisation. Nuclear factor $\kappa \mathrm{B}(\mathrm{NF}-\kappa \mathrm{B})$ activation promotes a proinflammatory state resulting in degradation of the endothelial glycocalyx, which may expose neutrophil ligands. CAMP levels increase in response to a range of mediators to induce activation of PKA (which inhibits RhoA) as well as the guanine exchange factor, exchange protein activated by CAMP (Epac). Epac (via Rap1) enhances VE-cadherin junctional integrity and actin reorganisation. Rap1 enhances barrier function via inhibition of Rho and activation of $\mathrm{Cdc42}$ as well as a cooperative association with VE-cadherin. Cdc42 directly regulates cortical actin organisation and proteins including MLCK and neural-Wiskott Aldrich syndrome protein (N-WASP) that mediate cortical actin formation via interaction with focal adhesion kinase (FAK) and actin-related protein (ARP) thus strengthening AJ and tight junction (TJ) formation as well as cell adhesion to the extracellular matrix (ECM). FAK also signals via effector molecules to inhibit RhoA and activate Rac1.

of focal adhesion formation by binding to focal adhesion proteins as well as enhancing AJ formation; ${ }^{6}$ in experimental ARDS models (including conditional FAK deletion), decreased FAK expression was associated with lung oedema as well as albumin and neutrophil influx. ${ }^{57}$

MLC-phosphorylation independent mechanisms of barrier disruption also exist. Endothelial cell apoptosis via mediators including $\mathrm{TNF}^{58}$ and influenza virus ${ }^{59}$ may contribute. Tyrosine phosphorylation of cytoskeletal proteins and adhesion molecules including VE-cadherin, $\beta$-catenin and p120 via tyrosine kinases including $\mathrm{Src}^{60}$ may induce disassembly of the catenincadherin complex ${ }^{61}{ }^{62}$ while microtubule disassembly independent of MLCK and Rho has been reported. ${ }^{63} 64$

The angiopoietin-Tie2 signalling axis (the endothelial tyrosine kinase Tie2 and its circulating ligands Ang-1-4) merits specific mention as a mediator of barrier disruption as it represents one of the most extensively studied barrier-regulating mechanisms. Ang- 1 is constitutively expressed in a range of cell types and mediates barrier integrity and endothelial quiescence via steady activation of the Tie 2 receptor, which is abundantly expressed in endothelium. Ang-2, released from endothelial cells in response to a diverse range of mediators, ${ }^{65} 66$ acts as a functional antagonist of Ang-1 at the Tie2 receptor, mediating cytoskeletal rearrangement ${ }^{25}$ and junctional disruption. ${ }^{67}$ Thus, mice heterozygous for Ang-2 were protected from lung injury compared with wild type mice in sepsis models. ${ }^{67}$ Ang-2 may play additional roles in leucocyte endothelial interactions. ${ }^{66}$ In the clinic, circulating levels of Ang-2 correlated with increased pulmonary oedema and mortality in patients with $\mathrm{ARDS}^{26}$ and predicted the development of ARDS in critical illness, ${ }^{68}$ further supporting a central role for Ang-2 in the endothelial injury of ARDS.

The role of damage-associated molecular patterns (native molecules released after tissue injury) and in particular mitochondrial DNA (mtDNA) production in barrier disruption is an emerging area of investigation. Hence, circulating levels of mtDNA are elevated in critical illness. ${ }^{69}$ In this context, they are potent inducers of the inflammasome via toll-like receptor 9 (TLR9), ${ }^{70}$ activating leucocyte-mediated lung injury when injected in vivo ${ }^{71}$ and endothelial barrier disruption in vitro. ${ }^{72}$ A bacterial challenge in isolated mouse lungs induced mtDNA release which was associated with endothelial hyperpermeability; this effect was replicated with exogenous mtDNA and attenuated by blockade of TLR9. ${ }^{73}$ Further elucidation of mechanisms of mtDNA release and their interplay with ROS as well as intracellular signalling pathways are required but this represents an intriguing line of investigation, if not a potential therapeutic target. While previously thought to contribute primarily to lung epithelial injury and repair, ${ }^{74}$ pathogen-associated molecular pattern (PAMP) signalling via pattern recognition receptors (PRRs) may also contribute to lung endothelial barrier dysfunction. Accordingly, influenza virus infection upregulated PRR expression (specifically TNF receptor 1) in a range of relevant models including human lung autopsy specimens, with 
resultant endothelial leak and apoptosis following exposure to Staphylococcus aureus-derived PAMPs in vitro. ${ }^{75}$

\section{CANDIDATE THERAPIES TO ENHANCE ENDOTHELIAL BARRIER FUNCTION}

The endogenous lipid growth factor sphingosine-1-phosphate (S1P) enhances barrier function through a series of signalling pathways that maintain cortical actin, focal adhesions and tight junctions (reviewed in ref. 76). S1P receptors are highly expressed on pulmonary endothelial cells. Accordingly, S1P and its analogues reduced vascular leakage in small and large animal lung injury models ${ }^{77} 78$ as well as dampened the cytokine storm in a murine influenza model. ${ }^{16}$ The clinical application of S1P and its analogues is currently limited by systemic toxicity, most notably immunosuppression prompting the use of FTY720 (an S1P analogue) in multiple sclerosis. ${ }^{79}$ Moreover, in a murine model, prolonged application of S1P agonists worsened vascular leakage and promoted fibrosis ${ }^{80}$ while the S1P pathway has been linked to dysregulated fibrogenesis of idiopathic pulmonary fibrosis. ${ }^{81}$ Safer analogues with promising, if not superior, preclinical data may however be on the horizon. ${ }^{82}$

Based on the preclinical and clinical data outlined above, the Tie2 axis represents an attractive therapeutic target. A stable variant of Ang-1 protected against systemic microvascular dysfunction and restored endothelial barrier function in a murine sepsis model, ${ }^{83}$ while Ang-1 therapy rescued barrier disruption in vitro from ARDS plasma high in Ang-2. Recent work has demonstrated that a specific pharmacological inhibitor of VEprotein tyrosine phosphatase catalytic activity, AKB-9778, which activates Tie $2,{ }^{84}$ blocked lung neutrophil recruitment in LPS-challenged mice and stabilised lung endothelial junctions via Rap1. ${ }^{85}$ A novel Tie-2 agonist rescued mice from severe influenza up to 3 days after infection. ${ }^{59}$ Improvements in vascular leak were attributed to Tie-2-mediated attenuation of endothelial cell apoptosis as cellular proliferation was unaffected. Notably, maintenance of barrier function did not impair leucocyte transmigration. This observation supports data from a study in systemic circulation suggesting independent regulation of these two processes. ${ }^{86} 87$

The renin-angiotensin system (RAS) is a complex network orchestrating blood pressure, electrolyte and fluid homoeostasis, that has been implicated in the pathogenesis of ARDS. ACE2 is an endogenous modulator of RAS highly expressed in the lung endothelium and alveolar epithelium ${ }^{88}$ which diverts potentially injurious angiotensin II (Ang II) signalling via conversion of Ang II to Ang 1-7 and inactivation of angiotensin receptors, thus negatively regulating RAS. ${ }^{89}$ Studies in knockout mice have demonstrated that loss of ACE2 worsened sepsis and acid aspiration induced lung injury. ${ }^{90}$ ACE2 is reported to be the receptor for the severe acute respiratory syndrome (SARS) coronavirus induced lung injury. ${ }^{91}$ More recently, compelling data suggest that ACE2 has a central role in the development and progression of the potentially lethal avian influenza viruses $\mathrm{H} 5 \mathrm{~N} 1^{92}$ and H797. ${ }^{93} 94$ Gain of function ACE1 polymorphisms are also associated with ARDS susceptibility and worse outcome. ${ }^{95}$ None of these studies offer clear mechanistic insight but ACE2 signalling in the lung is likely to be mediated by alveolar epithelial cells. ${ }^{88} 96$ A Phase IIa trial of a recombinant ACE2 compound in patients with both direct and indirect ARDS, Clinical Trials.gov ID: NCT01597635, has recently completed recruitment and interim results are awaited.

Pleomorphic, anti-inflammatory, immunomodulatory and antioxidant effects are exerted by 3-hydroxy-3-methylglutaryl coenzyme A reductase inhibitors (statins) on endothelial cells to promote cytoskeletal rearrangement, decrease oxidative stress and modulate gene expression. ${ }^{97} 98$ Hence, statins attenuated vascular leak in a range of murine ALI models. ${ }^{97} 99100$ Despite promising preclinical data, including an in vivo human inhaled LPS model, ${ }^{101}$ these findings were not translated into clinical improvements in two recent clinical trials. ${ }^{102}{ }^{103}$ Given the extensive data supporting a biological effect on the endothelium, it is intriguing to speculate that these trials may have been enriched by the enrolment of specific endotypes of patients with indirect ARDS to optimise outcomes.

A recent phase I clinical trial of 26 patients demonstrated mortality benefit in ARDS $(\mathrm{n}=37)$ treated with interferon- $\beta-1 \mathrm{a} .{ }^{104}$ The proposed mechanisms of benefit were modulation of inflammation (possibly neutrophil endothelial interactions) and endothelial barrier function via CD73-mediated dephosphorylation of AMP. While nonrandomised, the mortality benefit ( $24 \%$ absolute reduction) in this study suggests that targeting the lung endothelium may hold promise as a viable therapeutic strategy in ARDS. A randomised controlled trial is imminent to confirm these findings. This study was also notable by the generation of human (ex vivo) data to support animal data prior to early phase trials, a paradigm that should be increasingly adopted.

The pleiotropic effects of the tyrosine kinase inhibitor imatinib, particularly in attenuation of vascular permeability induced by a broad range of mediators (discussed in ${ }^{105}$ ), have stimulated study into its efficacy as a barrier-enhancing agent in ARDS. Despite imatinib's association with peripheral oedema, ${ }^{106}$ case reports have suggested clinical improvements in idiopathic vascular leak ${ }^{107}$ and bleomycin-induced lung injury. ${ }^{108}$ Supporting these clinical observations these clinical observations, imatinib attenuated thrombin and histamine-induced barrier dysfunction in vitro ${ }^{109}$ and pulmonary vascular leak in clinically relevant murine models. ${ }^{105}{ }^{109}$ Given its multiple sites of action (table 2), further mechanistic work is required to progress imatinib as a potential therapy in ARDS.

Other candidate therapies have shown promise, but again mechanistic understanding in the pulmonary vasculature is not sufficiently advanced. Atrial natriuretic peptide (ANP) protects against LPS-mediated lung microvascular leakage by blocking NF-kB activity, ${ }^{110}$ while concurrently enhancing VE-cadherin localisation to AJ. ${ }^{111}$ Recent murine data support an additional role for ANP in microtubule stabilisation, an emerging mechanism in regulation of endothelial cell permeability. ${ }^{112}$ Of note, a previous small clinical trial demonstrated physiological improvements with an infusion of ANP. ${ }^{113}$ Adrenomedullin (AM), a ubiquitously expressed peptide hormone that binds calcitonin receptor-like receptor on lung endothelial cells promoting intercellular adherence, improved endothelial barrier function in preclinical acute lung injury (ALI) and ventilator associated lung injury (VALI) models. ${ }^{114-116}$ Given the abundance of binding sites on the pulmonary endothelium, AM also holds promise as a lung endothelial imaging tool using $99 \mathrm{mTechnetium} \mathrm{label-}$ ling. ${ }^{117}$ Finally, hepatocyte growth factor has recently been shown to suppress LPS-induced endothelial activation and barrier disruption possibly via a guanine nucleotide exchange factor. ${ }^{118} 119$

A summary of the mediators and mechanisms of barrier disruption and enhancement is outlined in table 2 and figure 2 .

\section{INTERACTIONS OF THE LUNG MICROVASCULATURE WITH} LEUCOCYTES AND PLATELETS

Neutrophils are central to the initiation and propagation of inflammation and injury in ARDS and neutrophilic alveolitis is a 
Table 2 Mediators and mechanisms of barrier disruption and enhancement

\begin{tabular}{|c|c|c|c|}
\hline Molecule & Target & Mechanisms & Refs \\
\hline \multicolumn{4}{|l|}{ Barrier disruption } \\
\hline $\begin{array}{l}\text { Endothelial } \\
\text { glycocalyx }\end{array}$ & Unknown & $\begin{array}{l}\text { Loss of endothelial homoeostatic mechanisms } \\
\text { Disruption of cell-cell and cell-matrix interactions } \\
\text { Increased leucocyte adhesion }\end{array}$ & 12,13 \\
\hline LPS & TLR4 & $\begin{array}{l}\text { Intracellular calcium influx via DAG-induced TRPC6 channel activation } \\
\text { Reduced FAK expression } \\
\text { MLCK activation } \\
\text { NF- } \kappa \text { B induced inflammatory cytokine release }\end{array}$ & $41,57,120$ \\
\hline Mechanical stretch & IL-6R & $\begin{array}{l}\text { RhoA activation } \\
\text { Expression of contractile proteins } \\
\text { Cytokine release }\end{array}$ & $121-123$ \\
\hline mtDNA & TLR9 & $\begin{array}{l}\text { Intracellular calcium influx } \\
\text { Cytokine release }\end{array}$ & 72 \\
\hline ROS & NADPH oxidase & Intracellular calcium influx and MLCK activation & 20,21 \\
\hline Thrombin & PAR1 & Intracellular calcium influx and activation of MLCK and RhoA & 124,125 \\
\hline TNF & TNFR1 & $\begin{array}{l}\text { Promotion of NF- } \kappa B \text { induced inflammatory cytokine release and upregulation of } \\
\text { leucocyte ligands, for example, ICAM-1 }\end{array}$ & 17 \\
\hline \multicolumn{4}{|l|}{ Barrier enhancement } \\
\hline ACE2 & Not applicable & $\begin{array}{l}\text { Negative regulation of RAS via inactivation of angiotensin receptors } \\
\text { Abrogation of Ang II signalling and activity }\end{array}$ & 89,90 \\
\hline Adrenomedullin & CLR complex & $\begin{array}{l}\text { Attenuation of MLCK phosphorylation } \\
\text { Activation of protein kinase A, } \\
\text { Promotes intercellular adherence }\end{array}$ & 115,126 \\
\hline Ang1 & Tie2 & $\begin{array}{l}\text { Adherens junction assembly via Rac1 activation Inhibition of NF- } \kappa \text { B signalling } \\
\text { Competitive inhibition of Ang-2-mediated barrier disruption }\end{array}$ & 65 \\
\hline ANP & $N F-\kappa B$ & $\begin{array}{l}\text { Protects against LPS mediated NF- } \kappa B \text { signalling } \\
\text { Enhanced VE-cadherin localisation to AJ }\end{array}$ & 110,111 \\
\hline HGF & MET & Activates Rac-dependent cytoskeletal rearrangement & 118,119 \\
\hline IFN $\beta 1 \mathrm{a}$ & CD73 & Upregulation of CD73-enhancing adenosine activity via adenosine dephosphorylation & 104,127 \\
\hline Imatinib & $\begin{array}{l}\text { c-Abl } \\
\text { Arg } \\
\text { PDGFR }\end{array}$ & $\begin{array}{l}\text { Augmented Rac1 signalling } \\
\text { Cytoskeletal rearrangement } \\
\text { Inhibition of LPS-induced NF- } \kappa \text { B signalling }\end{array}$ & $105,109,128,129$ \\
\hline S1P & $\mathrm{S}_{\mathrm{PR}}$ & $\begin{array}{l}\text { Stabilisation of AJs via Rac1 } \\
\text { Inhibition of cofilin signalling enhancing TJ formation }\end{array}$ & 76,130 \\
\hline Statins & HMG-coenzyme A reductase & Abrogation of VEGF signalling via RhoA inhibition and Rac1 activation & $97,99,100$ \\
\hline \multicolumn{4}{|c|}{$\begin{array}{l}\text { AJ, adherens junction; Ang1/2, angiopoetin 1/2; ANP, atrial natriuretic peptide; Arg, Abl-related gene; CD73, cluster of differentiation 73; CLR, calcitonin receptor-like receptor; DAG, } \\
\text { diacyglycerol; FAK, focal adhesion kinase; HGF, hepatocyte growth factor; HMG, 3-hydroxy-3-methyl-glutanyl; ICAM-1, intracellular adhesion molecule; IFN } \beta 1 \text { a, interferon- } \beta \text { 1- } \alpha \text {; IL-6R, } \\
\text { interleukin-6 receptor; LPS, lipopolysaccharide; MET, hepatocyte growth factor receptor; MLCK, myosin light chain kinase; mtDNA, mitochondrial DNA; NADPH, nicotinamide adenine } \\
\text { dinucleotide phosphate; NF- } \mathrm{B} B \text {, nuclear factor } \kappa B ; \text { PAR1, protease-activated receptor; PDGFR: platelet-derived growth factor receptor; RhoA, Ras homologue gene family, member A; } \\
\text { RAS, renin-angiotensin system; ROS, reactive oxygen species; Tie2, tyrosine kinase receptor-2; TJ, tight junction; TLR4, toll-like receptor 4; TLR9, toll-like receptor 9; TNF, tumour necrosis } \\
\text { factor; TNFR1, tumour necrosis factor receptor 1; TRPC6, transient receptor potential cation channel, member 6; S1P, sphingosine-1-phosphate; S1PR } 1 \text {, sphingosine-1-phosphate receptor } \\
\text { 1; VE-cadherin; vascular endothelial cadherin; VEGF, vascular endothelial growth factor. }\end{array}$} \\
\hline
\end{tabular}

histological hallmark. ${ }^{131}$ Their importance in ARDS is highlighted by the observation that a decline in respiratory function is seen in neutropenic patients with ARDS upon recovery of neutrophil counts. ${ }^{132}$ Pathway analysis of differential gene expression in sepsis-induced ARDS compared with sepsis alone identified a preponderance of genes regulating neutrophil homoeostasis and activation, ${ }^{133}$ further supporting the notion of the role of neutrophilic inflammation.

Despite extensive data from models of the systemic circulation (eg, murine cremaster vessels and human umbilical vein endothelial cells), our mechanistic understanding of the role of the pulmonary endothelium in neutrophil sequestration is limited. As a consequence of the unique pulmonary capillary microanatomy, the site and mechanisms of neutrophil sequestration are different from the systemic microcirculation. For example, owing to space constraints in the alveolar capillary bed, neutrophils must change their shape to pass through. Moreover, neutrophil rolling on the endothelial surface does not occur. ${ }^{134}$ Similarly, neutrophils exhibit selectin and CD11b/CD18independent sequestration in pulmonary capillaries. ${ }^{135} 136 \mathrm{~A}$ role for the endothelial glycocalyx in modulation of neutrophil adhesion molecule expression (ICAM-1) has been proposed, ${ }^{12}$ however, precise identification of the cognate receptors for neutrophils on lung endothelium remains elusive and further study in refined animal models and novel human models is an urgent unmet need.

Clarification of the role of neutrophil migration in barrier disruption is also required. Activated neutrophils exert negative effects on barrier permeability via secretion of various products such as TNF, complement component $5 \mathrm{a}$ and arachidonic acid but it remains unclear whether neutrophil migration through the endothelium is damaging per se. As outlined above, recent data support the concept that neutrophil migration and endothelial barrier disruption may be independently regulated. ${ }^{598687}$

Recent work has focused on the role of the transient receptor potential (TRP) channels, specifically TRP vanilloid 4 (TRPV4) receptor, particularly as it is expressed on both neutrophils and the pulmonary endothelium, and specific inhibitors are available. ${ }^{137}$ TRPV4 signalling has been implicated in endothelial dysfunction secondary to mechanical ${ }^{138}$ and hydrostatic ${ }^{139}$ stress possibly via calcium influx. ${ }^{137} 140$ Deletion of TRPV4 attenuated both endothelial barrier leak and neutrophil 


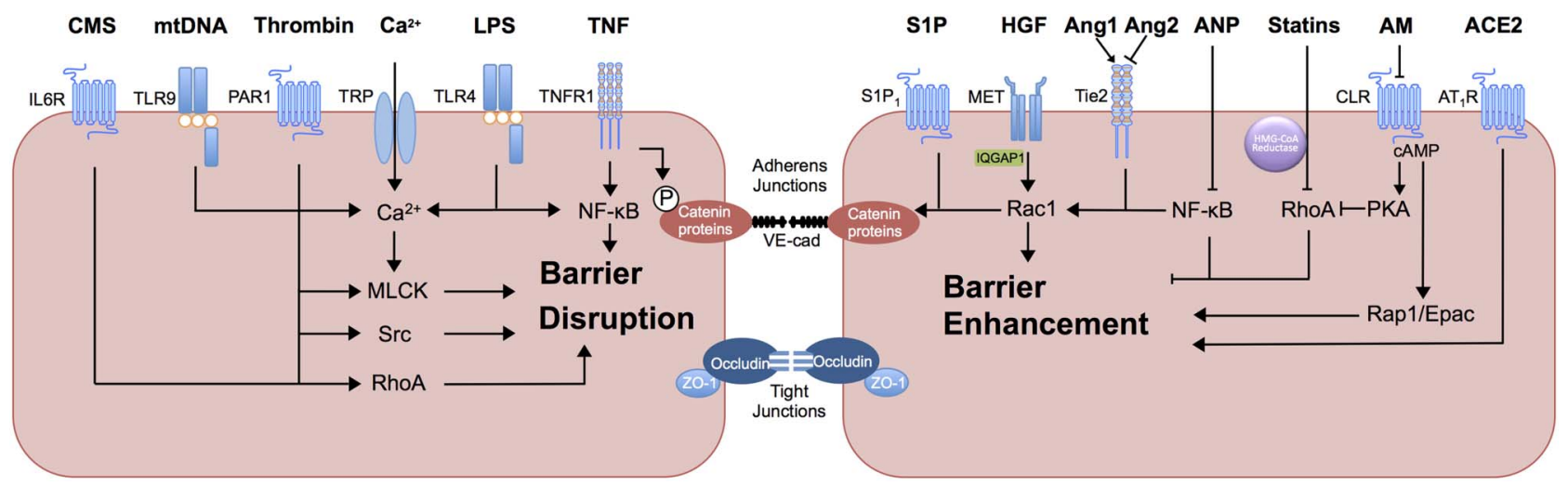

Figure 2 Mediators of pulmonary endothelial barrier function. Thrombin acts via protease activated receptor 1 (PAR1) to induce multiple barrier disruptive mechanisms including calcium influx, via transient receptor potential (TRP) ion channels, adherens junction (AJ) protein phosphorylation via the tyrosine kinase Src and RhoA activation. Lipopolysaccharide (LPS), via activation of toll-like receptor 4 (TLR4), increases intracellular calcium and activates myosin light chain kinase (MLCK) as well as induction of nuclear factor $\kappa B$ (NF- $\kappa B$ ) signalling, promoting inflammatory cytokine production and neutrophil ligand expression. Mitochondrial DNA (mtDNA) acts via toll-like receptor 9 (TLR9) to increase intracellular calcium, activate MLCK and promote actin stress fibre formation. Cyclic mechanical stretch (CMS), via interleukin 6 receptor (IL6R) disrupts barrier function via Rho-independent mechanisms (circulating IL-6) and Rho-dependent mechanisms. Tumour necrosis factor $\alpha$ (TNF), via TNF receptor 1 (TNFR1) activates NF- $\kappa$ B. An additional mechanism of TNF-induced barrier disruption includes tyrosine phosphorylation of vascular endothelial cadherin (VE-cadherin). Barrier protective mediators sphingosine-1-phosphate (S1P) activates sphingosine-1-phosphate receptor 1 (S1 $\mathrm{P}_{1}$ ) to promote MLC phosphorylation and AJ assembly via Rac1. S1P signalling may have additional immunomodulatory effects in influenza infection. Hepatocyte growth factor (HGF), via HGF receptor tyrosine kinase (MET) activates Rac1 activity via the adaptor protein IQGAP1. Angiopoetin-1 (Ang-1) competes with the functional antagonist Ang-2 at the tyrosine kinase with immunoglobulin-like and EGF-like domains 2 (Tie2) receptor to promote $\mathrm{AJ}$ assembly and cortical actin formation through Rac1 and inhibition of NF- $\mathrm{KB}$ signalling. Atrial natriuretic peptide (ANP) also mitigates proinflammatory NF- $\kappa B$ signalling and RhoA activity. 3-hydroxy-3-methylglutaryl coenzyme reductase inhibitors (statins) inhibit RhoA activity. ACE2 acts via angiotensin 2 type 1 receptor $\left(A T_{1} R\right)$ to inhibit the barrier-disruptive effects of Angiotensin 2 signalling and renin-angiotensin system activation. Adrenomedullin (AM) acts via calcitonin receptor-like receptor (CLR) to activate cyclic AMP (cAMP) signalling, mediating barrier enhancement via protein kinase A (PKA)-induced RhoA inhibition and endothelial cell contraction as well as Rap- mediated exchange protein activated by CAMP (Epac) activation.

activation in a murine acid injury model. ${ }^{137}$ Further, chimerical mouse models demonstrated that attenuation of lung injury was contingent on endothelial TRPV4 as opposed to leucocyte TRPV4 although deletion of TRPV on neutrophils did abrogate injury in isolated perfused mouse lungs. ${ }^{137}$

The concept that the lung endothelium may play a role in host defence by facilitating the depriming of neutrophils and hence providing protection from neutrophil-mediated remote organ injury, has been proposed. Data from an in vivo human model demonstrated that the healthy lung microvasculature retained primed cells and subsequently facilitated their depriming and release (into the systemic circulation) in an unprimed quiescent state. ${ }^{141}$ It is conceivable that failure of this mechanism, for example, as a consequence of endothelial injury in ARDS, may result in high circulating levels of primed neutrophils, which correlates with the severity of lung injury ${ }^{142}$ and which may mediate multi-organ dysfunction. Manipulation of this depriming mechanism may offer a novel therapeutic approach.

While platelets play a role in a range of pathobiological processes in ARDS (reviewed in ref. 143), our understanding of platelet endothelial interactions is underdeveloped and extrapolated from work on the systemic vasculature. In murine ARDS, platelets induced ICAM-1 expression on endothelial cells, propagating neutrophil extravasation. ${ }^{144}$ Experimental lung injury models have also demonstrated that platelets induce endothelial activation as evidenced by increased expression of vWF, P-selectin and tissue factor, such that platelet depletion and blockade of platelet binding ameliorated injury. ${ }^{145} 146$ Platelets also modulate endothelial barrier permeability through expression of a range of factors, including S1P (reviewed in ref. 147). Of note, however, in murine pneumonia, thrombocytopenia enhanced lung inflammation and endothelial cell activation suggesting that platelet depletion strategies may be detrimental. ${ }^{148}$ The interplay between neutrophil extracellular traps and platelets is an emerging narrative in lung injury secondary to blood transfusion ${ }^{149}$ and following lung transplantation. ${ }^{150}$ Platelet-endothelial interaction may also play a role in regulating alveologenesis (see below, ${ }^{151}$ ) and hence lung repair after injury.

\section{MODULATION OF THE COAGULATION CASCADE}

Activated coagulation and depressed fibrinolysis coupled with low circulating levels of endogenous anticoagulants contribute to the pathological and physiological features of ARDS. Moreover, it is becoming increasingly apparent that inflammation and coagulation in ARDS are intimately linked. ${ }^{152}$ Modulation of these effects has thus been an attractive therapeutic target.

The protein $\mathrm{C}$ pathway, in particular, has been the focus of extensive research, at least in the systemic circulation (reviewed in ref. 153). Activated protein $\mathrm{C}$ (APC) is generated from EPCR-bound protein $\mathrm{C}$ by TM-bound thrombin. EPCRs are expressed on both pulmonary artery and lung microvascular endothelial cells. ${ }^{154}$ In addition to its anticoagulant activity, APC manifests a myriad of cytoprotective effects, including antiapoptotic and anti-inflammatory effects through dissociation of APC from EPCR and activation of protease-activated receptor (PAR)-1 (and to a lesser extent PAR-3) biased signalling. ${ }^{153}{ }^{155}$ In the lung macrovascular endothelium, APC enhanced barrier function in a contextspecific fashion via S1P and RAC1-dependent mechanisms. ${ }^{130}$

Despite extensive preclinical data, recombinant APC demonstrated no clinical efficacy in patients with $\operatorname{ARDS}^{156}$ and no reduction in barrier leak was demonstrated with recombinant APC therapy, ${ }^{157}$ despite attenuation of the coagulopathy. ${ }^{158} \mathrm{~A}$ 
multicentre trial of modified (catalytic site irreversibly blocked) recombinant factor VIIa, ${ }^{159}$ similarly, showed no benefit. Thus, we have yet to fully harness the abilities of anticoagulants to modulate cell signalling, inflammation and barrier function, in particular via PAR signalling. ${ }^{130} 153$ These negative trial data may temper enthusiasm for ongoing research in this area. Nonetheless, PAR-1 antagonism has recently shown beneficial effects on neutrophil migration, cytokine release and barrier disruption in a murine pneumonia mode ${ }^{160}$ suggesting that alternative targets in the pathway may hold therapeutic promise.

\section{THE LUNG ENDOTHELIUM AND REPAIR IN ARDS}

The observation that over half of patients with ARDS survive, ${ }^{161}$ suggests that the lung microvascular endothelium and epithelium have a significant capacity for repair and regeneration. The process of repair following ARDS involves both alveolar and endothelial cell reconstitution with restoration of barrier function facilitating removal of alveolar oedema and inflammatory debris. A comprehensive discussion of endothelial repair is beyond the scope of this article and readers are referred to recent expert reviews. ${ }^{162} 163$

In addition to circulating progenitor cells, local populations of endothelial progenitor cells (EPCs) have been identified in the pulmonary microvascular endothelium ${ }^{164}$ and levels of EPCs are elevated in patients with ARDS. ${ }^{165}{ }^{166}$ Retrospective analysis of lung tissue from patients with male-to-female haematopoietic stem cell transplant provides direct evidence of integration of male EPCs into female recipient pulmonary endothelium confirming the role of EPCs. ${ }^{167}$ However, the field of circulating EPCs remains controversial; their origin and function as well as their ability to effect repair under the hostile environment of clinical ARDS remains uncertain. Moreover, the cell most commonly studied, (identified by Asahara in $1997^{168}$ ) is now recognised as a monocyte with angiogenic features and not a true endothelial progenitor. ${ }^{169}$ Furthermore, it has been demonstrated that the majority of endothelial repairs, at least after endotoxin-induced lung injury, was affected by tissue-resident progenitor cells, not circulating EPCs. ${ }^{170}$ Any therapeutic role of cell-based therapies may be anti-inflammatory, via secretion of paracrine factors, as opposed to mediating endothelial repair per se.

Alternatively, endothelial cells may modulate neoalveolarisation via crosstalk with their local niche. Hence, in murine pneumonectomy models platelet-endothelial interaction via stromal-cell derived factor- $1^{151}$ and lung endothelial vascular endothelial growth factor signalling (via the production of matrix metalloproteinase 14$)^{171}$ induced alveologenesis. Similarly, lung endothelial cells were required to support alveolar stem cell differentiation in vitro and lung regeneration in vivo; this mechanism was thrombospondin-1 (an endogenous inhibitor of angiogenesis) dependent. ${ }^{172}$

These data provide compelling evidence that the pulmonary endothelium participates in the resolution of ARDS. Whether manipulation of these endothelial niches or the administration and mobilisation of EPC populations is a feasible goal in ARDS requires further study. Further definition of the molecular pathways that regulate the crosstalk between endothelial cells and the reparative niche, particularly in the context of relevant ARDS models will be invaluable. While primarily directed towards resolution of alveolar epithelial inflammation and injury, data from a clinical trial of mesenchymal stem cells ${ }^{173}$ (ClinicalTrials.gov: NCT02097641) will hopefully provide additional insights, particularly regarding the effects of antiinflammatory strategies on endothelial barrier function and a potential interplay with endothelial cells.

\section{FUTURE DIRECTIONS}

The identification and validation of robust biomarkers to phenotype patients with ARDS to either identify them as having a predominance of endothelial injury or to predict response to treatment would appear an integral component influencing the success of future trials of novel endothelial therapeutics in ARDS. The application of 'omics' technologies such as metabolomics (reviewed in ref. 174) will hopefully advance this field in the coming years facilitating personalised therapies within the next decade. Biomarker exploration will ideally also result in the identification of novel druggable targets. Building on the work by Calfee et al, ${ }^{27} 2833175$ enrichment of patient enrolment into focused clinical trials of novel endothelial-specific therapeutics using established biomarkers would appear to be a reasonable strategy to optimise patient outcomes.

Further, it is imperative that the heterogeneity between systemic and pulmonary vascular endothelium and between animals and humans is increasingly recognised. Developing better techniques to interrogate neutrophil-endothelial interactions in the lung would seem paramount; the continued development of live imaging in transgenic mice using fluorescent probes to label specific cell types ${ }^{176}$ and increased application of isolated perfused lung models ${ }^{177}$ as well as human ex vivo and in vivo models represent mechanisms to maximise the translation of preclinical data into effective therapeutics. It remains to be seen whether the so-called 'lungs on a chip', ${ }^{178}$ which combine biomimetic systems containing microfluidic channels lined by living human cells, will develop into tractable models for lung biology per se or specifically ARDS pathobiology. An IL-2-induced injury model recapitulated salient features of in vivo ARDS, which were attenuated by a novel TRPV4 antagonist. ${ }^{179}$ This technology has the potential to complement (if not replace) current ARDS research platforms, facilitating interrogation of hitherto underdeveloped aspects of lung endothelial biology and pharmacology in a coculture platform with biologically relevant cell types (alveolar epithelial cells, lung microvascular endothelial cells and leucocytes or platelets) exposed to physiologically relevant mechanical forces via a stretchable porous membrane. ${ }^{180}$ The applications of threedimensional bioprinting for the study of lung biology ${ }^{181}$ similarly represents an enticing, if yet unrealised, prospect. Development of such innovative, humanised models coupled with the refinement of existing models will be central to the identification and testing of emerging therapeutics.

\section{CONCLUSIONS}

The pulmonary endothelium is increasingly seen as pivotal in both the progression and the resolution of ARDS and is therefore primed as a therapeutic target. Our understanding of endothelial biology, notably neutrophil-endothelial interactions in the lung vasculature, is a limitation to potential progress. Despite this, enhancement of endothelial barrier function, in particular, shows promise in preclinical models of ARDS and relevant latephase human trials are imminent. Novel imaging techniques and innovative in vitro research platforms may facilitate translation of promising animal data into efficacious endothelial-specific therapies. Despite enthusiasm for their introduction, the use of cell-based therapies requires further characterisation of their phenotype, efficacy and safety. In the interim, the application of emerging technologies will assist the search for robust biomarkers of endothelial injury, which will inevitably enhance enrolment into future clinical trials of novel lung endothelial-targeted agents.

Twitter Follow Alastair Proudfoot at @ICUDocAP 
Acknowledgements This work was supported by the Royal Brompton and Harefield NHS Foundation Trust, NIHR Respiratory Biomedical Research Unit, London, UK.

Collaborators Stefan Jovinge.

Funding CS is a Wellcome Trust Postdoctoral Clinical Research Training Fellow (WT101692MA).

Competing interests CS was a co-investigator on a project grant funded by GlaxoSmithKline, which undertook preclinical assessment of the effects of a potential ARDS therapy on human neutrophils (2012-2014). MJG and CS have received consultancy fees from GlaxoSmithKline. MJG and AGP have had unrestricted project grant support from GlaxoSmithKline.

Provenance and peer review Not commissioned; externally peer reviewed.

\section{REFERENCES}

1 Zimmerman GA, Albertine $\mathrm{KH}$, Carveth $\mathrm{HJ}$, et al. Endothelial activation in ARDS Chest 1999;116(1 Suppl):18S-24S.

2 Erickson SE, Martin GS, Davis JL, et al. Recent trends in acute lung injury mortality: 1996-2005. Crit Care Med 2009;37:1574-9.

3 Hager DN. Recent advances in the management of the acute respiratory distress syndrome. Clin Chest Med 2015;36:481-96.

4 Aird WC. Phenotypic heterogeneity of the endothelium: II. Representative vascular beds. Circ Res 2007;100:174-90.

5 Aird WC. Phenotypic heterogeneity of the endothelium: I. Structure, function, and mechanisms. Circ Res 2007;100:158-73.

6 Sukriti S, Tauseef M, Yazbeck P, et al. Mechanisms regulating endothelial permeability. Pulm Circ 2014;4:535-51.

7 Dudek SM, Garcia JG. Cytoskeletal regulation of pulmonary vascular permeability. J App/ Physiol 2001;91:1487-500.

8 Schulte D, Kuppers V, Dartsch N, et al. Stabilizing the VE-cadherin-catenin complex blocks leukocyte extravasation and vascular permeability. EMBO J 2011;30:4157-70.

9 Rothberg KG, Heuser JE, Donzell WC, et al. Caveolin, a protein component of caveolae membrane coats. Cell 1992;68:673-82.

10 Sun $Y, H u$ G, Zhang $X$, et al. Phosphorylation of caveolin-1 regulates oxidantinduced pulmonary vascular permeability via paracellular and transcellular pathways. Circ Res 2009;105:676-85.

11 Mehta $D$, Malik $A B$. Signaling mechanisms regulating endothelial permeability. Physiol Rev 2006;86:279-367.

12 Schmidt EP, Yang Y, Janssen WJ, et al. The pulmonary endothelial glycocalyx regulates neutrophil adhesion and lung injury during experimental sepsis. Nat Med 2012;18:1217-23.

13 Cioffi DL, Pandey S, Alvarez DF, et al. Terminal sialic acids are an important determinant of pulmonary endothelial barrier integrity. Am J Physiol Lung Cell Mol Physiol 2012;302:L1067-77.

14 Collins SR, Blank RS, Deatherage LS, et al. Special article: the endothelial glycocalyx: emerging concepts in pulmonary edema and acute lung injury. Anesth Analg 2013;117:664-74.

15 Goldenberg NM, Kuebler WM. Endothelial cell regulation of pulmonary vascular tone, inflammation, and coagulation. Comprehensive Physiology 2015;5:531-59.

16 Teijaro JR, Walsh KB, Cahalan S, et al. Endothelial cells are central orchestrators of cytokine amplification during influenza virus infection. Cell 2011;146:980-91.

17 Proudfoot AG, O'Kane CM, Bayliffe A, et al. A novel TNFR1-targeting domain antibody attenuates pulmonary inflammation in a human model of lung injury, via actions on the lung micro-vascular endothelium. Am J Respir Crit Care Med: Am Thorac Soc 2014;18:A6589.

18 Zhang K, Wang P, Huang S, et al. Different mechanism of LPS-induced calcium increase in human lung epithelial cell and microvascular endothelial cell: a cell culture study in a model for ARDS. Mol Biol Rep 2014;41:4253-9.

19 Rowlands DJ, Islam MN, Das SR, et al. Activation of TNFR1 ectodomain shedding by mitochondrial $\mathrm{Ca} 2+$ determines the severity of inflammation in mouse lung microvessels. J Clin Invest 2011;121:1986-99.

20 Gorbunov NV, Das DK, Goswami SK, et al. Spatial coordination of cell-adhesion molecules and redox cycling of iron in the microvascular inflammatory response to pulmonary injury. Antioxid Redox Signal 2007;9:483-95.

21 Boueiz A, Hassoun PM. Regulation of endothelial barrier function by reactive oxygen and nitrogen species. Microvasc Res 2009;77:26-34.

22 Bachofen M, Weibel ER. Alterations of the gas exchange apparatus in adult respiratory insufficiency associated with septicemia. Am Rev Respir Dis 1977;116:589-615.

23 Radomski MW, Palmer RM, Moncada S. Endogenous nitric oxide inhibits human platelet adhesion to vascular endothelium. Lancet 1987;2:1057-8.

24 Nuckton TJ, Alonso JA, Kallet RH, et al. Pulmonary dead-space fraction as a risk factor for death in the acute respiratory distress syndrome. N Engl J Med 2002;346:1281-6.
25 Parikh SM, Mammoto T, Schultz A, et al. Excess circulating angiopoietin-2 may contribute to pulmonary vascular leak in sepsis in humans. PLoS Med 2006;3:e46.

26 Calfee CS, Gallagher D, Abbott J, et al. Plasma angiopoietin-2 in clinical acute lung injury: prognostic and pathogenetic significance. Crit Care Med 2012;40:1731-7.

27 Schmidt EP, Li G, Li L, et al. The circulating glycosaminoglycan signature of respiratory failure in critically ill adults. J Biol Chem 2014;289:8194-202.

28 Sapru A, Calfee CS, Liu KD, et al. Plasma soluble thrombomodulin levels are associated with mortality in the acute respiratory distress syndrome. Intensive Care Med 2015:41:470-8.

29 Terpstra ML, Aman J, van Nieuw Amerongen GP, et al. Plasma biomarkers for acute respiratory distress syndrome: a systematic review and meta-analysis* ${ }^{*}$ Crit Care Med 2014:42:691-700.

30 McVey M, Tabuchi A, Kuebler WM. Microparticles and acute lung injury. Am J Physiol Lung Cell Mol Physiol 2012;303:L364-81.

31 Cabrera-Benitez NE, Valladares F, Garcia-Hernandez S, et al. Altered profile of circulating endothelial-derived microparticles in ventilator-induced lung injury. Crit Care Med 2015;43:551-9.

32 Letsiou E, Sammani S, Zhang W, et al. Pathologic mechanical stress and endotoxin exposure increases lung endothelial microparticle shedding. Am J Respir Cell Mol Biol 2015:52:193-204.

33 Calfee CS, Delucchi K, Parsons PE, et al. Subphenotypes in acute respiratory distress syndrome: latent class analysis of data from two randomised controlled trials. Lancet Respir Med 2014;2:611-20.

34 Shuvaev VV, Han J, Yu KJ, et al. PECAM-targeted delivery of SOD inhibits endothelial inflammatory response. FASEB J 2011;25:348-57.

35 Ferrer MC, Shuvaev VV, Zern BJ, et al. Icam-1 targeted nanogels loaded with dexamethasone alleviate pulmonary inflammation. PLOS ONE 2014;9:e102329.

36 Greineder CF, Brenza JB, Carnemolla R, et al. Dual targeting of therapeutics to endothelial cells: collaborative enhancement of delivery and effect. FASEB J 2015;29:3483-92.

37 Hurley JV. Types of pulmonary microvascular injury. Ann N Y Acad Sci 1982:384:269-86.

38 Kamm KE, Stull JT. Dedicated myosin light chain kinases with diverse cellular functions. J Biol Chem 2001;276:4527-30.

39 Garcia JG, Liu F, Verin AD, et al. Sphingosine 1-phosphate promotes endothelial cell barrier integrity by Edg-dependent cytoskeletal rearrangement. J Clin Invest 2001;108:689-701.

40 Liu F, Schaphorst KL, Verin AD, et al. Hepatocyte growth factor enhances endothelial cell barrier function and cortical cytoskeletal rearrangement: potential role of glycogen synthase kinase-3beta. FASEB J 2002;16:950-62.

41 Wainwright MS, Rossi J, Schavocky J, et al. Protein kinase involved in lung injury susceptibility: evidence from enzyme isoform genetic knockout and in vivo inhibito treatment. Proc Natl Acad Sci USA 2003;100:6233-8.

42 Wojciak-Stothard B, Potempa S, Eichholtz T, et al. Rho and Rac but not Cdc42 regulate endothelial cell permeability. J Cell Sci 2001;114(Pt 7):1343-55.

43 Broman MT, Mehta D, Malik AB. Cdc42 regulates the restoration of endothelial adherens junctions and permeability. Trends Cardiovasc Med 2007:17:151-6.

44 Barry DM, Xu K, Meadows SM, et al. Cdc42 is required for cytoskeletal support of endothelial cell adhesion during blood vessel formation in mice. Development 2015; 142:3058-70.

45 Birukova AA, Smurova K, Birukov KG, et al. Role of Rho GTPases in thrombin-induced lung vascular endothelial cells barrier dysfunction. Microvasc Res 2004;67:64-77.

46 Joshi AD, Dimitropoulou C, Thangjam G, et al. Heat shock protein 90 inhibitors prevent LPS-induced endothelial barrier dysfunction by disrupting RhoA signaling. Am J Respir Cell Mol Biol 2014:50:170-9.

47 Kimura K, Ito M, Amano M, et al. Regulation of myosin phosphatase by Rho and Rho-associated kinase (Rho-kinase). Science 1996:273:245-8.

48 Mehta D, Konstantoulaki M, Ahmmed GU, et al. Sphingosine 1-phosphateinduced mobilization of intracellular $\mathrm{Ca} 2+$ mediates rac activation and adherens junction assembly in endothelial cells. J Biol Chem 2005;280:17320-8.

49 Naikawadi RP, Cheng N, Vogel SM, et al. A critical role for phosphatidylinositol $(3,4,5)$-trisphosphate-dependent Rac exchanger 1 in endothelial junction disruption and vascular hyperpermeability. Circ Res 2012;111:1517-27.

50 Daneshjou N, Sieracki N, van Nieuw Amerongen GP, et al. Rac1 functions as a reversible tension modulator to stabilize VE-cadherin trans-interaction. J Cell Biol 2015:208:23-32.

51 Ando K, Fukuhara S, Moriya T, et al. Rap1 potentiates endothelial cell junctions by spatially controlling myosin II activity and actin organization. J Cell Biol 2013;202:901-16.

52 Pannekoek WJ, Post A, Bos JL. Rap1 signaling in endothelial barrier control. Cell Adh Migr 2014;8:100-7.

53 Cullere X, Shaw SK, Andersson L, et al. Regulation of vascular endothelial barrier function by Epac, a cAMP-activated exchange factor for Rap GTPase. Blood 2005; 105:1950-5.

54 Schmidt M, Evellin S, Weernink PA, et al. A new phospholipase-C-calcium signalling pathway mediated by cyclic AMP and a Rap GTPase. Nat Cell Biol 2001;3:1020-4. 
55 Sayner SL. Emerging themes of CAMP regulation of the pulmonary endothelial barrier. Am J Physiol Lung Cell Mol Physiol 2011;300:L667-78.

56 Qiao J, Huang F, Lum H. PKA inhibits RhoA activation: a protection mechanism against endothelial barrier dysfunction. Am J Physiol Lung Cell Mol Physiol 2003;284:L972-80.

57 Schmidt TT, Tauseef M, Yue L, et al. Conditional deletion of FAK in mice endothelium disrupts lung vascular barrier function due to destabilization of RhoA and Rac1 activities. Am J Physiol Lung Cell Mol Physiol 2013;305: L291-300.

58 Haimovitz-Friedman A, Cordon-Cardo C, Bayoumy S, et al. Lipopolysaccharide Induces Disseminated Endothelial Apoptosis Requiring Ceramide Generation. J Exp Med 1997;186:1831-41.

59 Sugiyama MG, Armstrong SM, Wang C, et al. The Tie2-agonist Vasculotide rescues mice from influenza virus infection. Sci Rep 2015;5:11030.

60 Gong P, Angelini DJ, Yang S, et al. TLR4 Signaling is coupled to SRC family kinase activation, tyrosine phosphorylation of zonula adherens proteins, and opening of the paracellular pathway in human lung microvascular endothelia. J Biol Chem 2008;283:13437-49.

61 Vandenbroucke St Amant E, Tauseef M, Vogel SM, et al. PKC $\alpha$ activation of p120-catenin serine 879 phospho-switch disassembles VE-cadherin junctions and disrupts vascular integrity. Circ Res 2012;111:739-49.

62 Gong H, Gao X, Feng S, et al. Evidence of a common mechanism of disassembly of adherens junctions through Go13 targeting of VE-cadherin. J Exp Med 2014;211:579-91.

$63 \mathrm{Li} \mathrm{L}, \mathrm{Hu}$ J, He T, et al. P38/MAPK contributes to endothelial barrier dysfunction via MAP4 phosphorylation-dependent microtubule disassembly in inflammationinduced acute lung injury. Sci Rep 2015;5:8895.

64 Petrache I, Birukova A, Ramirez SI, et al. The role of the microtubules in tumor necrosis factor- $\alpha$-induced endothelial cell permeability. Am J Resp Cell Mol 2003;28:574-81.

65 Parikh SM. Dysregulation of the angiopoietin-Tie-2 axis in sepsis and ARDS. Virulence 2013:4:517-24.

66 Fiedler U, Reiss Y, Scharpfenecker M, et al. Angiopoietin-2 sensitizes endothelial cells to TNF-alpha and has a crucial role in the induction of inflammation. Nat Med 2006;12:235-9.

67 David S, Mukherjee A, Ghosh CC, et al. Angiopoietin-2 may contribute to multiple organ dysfunction and death in sepsis ${ }^{*}$. Crit Care Med 2012;40:3034-41.

68 Agrawal A, Matthay MA, Kangelaris KN, et al. Plasma angiopoietin-2 predicts the onset of acute lung injury in critically ill patients. Am J Respir Crit Care Med 2013;187:736-42.

69 Nakahira K, Kyung SY, Rogers AJ, et al. Circulating mitochondrial DNA in patients in the ICU as a marker of mortality: derivation and validation. PLOS Med 2013;10: e1001577.

70 Nakahira K, Haspel JA, Rathinam VA, et al. Autophagy proteins regulate innate immune responses by inhibiting the release of mitochondrial DNA mediated by the NALP3 inflammasome. Nat Immunol 2011;12:222-30.

71 Zhang Q, Raoof M, Chen Y, et al. Circulating mitochondrial DAMPs cause inflammatory responses to injury. Nature 2010;464:104-7.

72 Sun S, Sursal T, Adibnia Y, et al. Mitochondrial DAMPs increase endothelial permeability through neutrophil dependent and independent pathways. PLOS ONE 2013:8:e59989.

73 Kuck JL, Obiako BO, Gorodnya OM, et al. Mitochondrial DNA damage-associated molecular patterns mediate a feed-forward cycle of bacteria-induced vascular injury in perfused rat lungs. Am J Physiol Lung Cell Mol Physiol 2015;308: L1078-85.

74 Jiang D, Liang J, Fan J, et al. Regulation of lung injury and repair by Toll-like receptors and hyaluronan. Nat Med 2005;11:1173-9.

75 Wang C, Armstrong SM, Sugiyama MG, et al. Influenza-induced priming and leak of human lung microvascular endothelium upon exposure to staphylococcus aureus. Am J Resp Cell Mol 2015;53:459-70.

76 Natarajan V, Dudek SM, Jacobson JR, et al. Sphingosine-1-phosphate, FTY720, and sphingosine-1-phosphate receptors in the pathobiology of acute lung injury. Am J Respir Cell Mol Biol 2013;49:6-17.

77 Mathew $B$, Jacobson JR, Berdyshev $E$, et al. Role of sphingolipids in murine radiation-induced lung injury: protection by sphingosine 1-phosphate analogs. FASEB J 2011;25:3388-400.

78 Szczepaniak WS, Zhang Y, Hagerty S, et al. Sphingosine 1-phosphate rescues canine LPS-induced acute lung injury and alters systemic inflammatory cytokine production in vivo. Trans/ Res 2008;152:213-24.

79 Pelletier D, Hafler DA. Fingolimod for multiple sclerosis. N Engl J Med 2012:366:339-47.

80 Shea BS, Brooks SF, Fontaine BA, et al. Prolonged exposure to sphingosine 1-phosphate receptor-1 agonists exacerbates vascular leak, fibrosis, and mortality after lung injury. Am J Respir Cell Mol Biol 2010;43:662-73.

81 Huang LS, Berdyshev EV, Tran JT, et al. Sphingosine-1-phosphate lyase is an endogenous suppressor of pulmonary fibrosis: role of S1P signalling and autophagy. Thorax 2015;70:1138-48.
82 Wang L, Bittman R, Garcia JG, et al. Junctional complex and focal adhesion rearrangement mediates pulmonary endothelial barrier enhancement by FTY720 S-phosphonate. Microvasc Res 2015;99:102-9.

83 Alfieri A, Watson JJ, Kammerer RA, et al. Angiopoietin-1 variant reduces LPS-induced microvascular dysfunction in a murine model of sepsis. Crit Care 2012;16:R182.

84 Shen J, Frye M, Lee BL, et al. Targeting VE-PTP activates TIE2 and stabilizes the ocular vasculature. J Clin Invest 2014;124:4564-76.

85 Frye M, Dierkes $M$, Küppers V, et al. Interfering with VE-PTP stabilizes endothelial junctions in vivo via Tie-2 in the absence of VE-cadherin. J Exp Med 2015:212:2267-87.

86 Phillipson M, Kaur J, Colarusso $\mathrm{P}$, et al. Endothelial domes encapsulate adherent neutrophils and minimize increases in vascular permeability in paracellular and transcellular emigration. PLOS ONE 2008;3:e1649.

87 Wessel F, Winderlich M, Holm M, et al. Leukocyte extravasation and vascular permeability are each controlled in vivo by different tyrosine residues of VE-cadherin. Nat Immunol 2014;15:223-30.

88 Hamming I, Timens W, Bulthuis ML, et al. Tissue distribution of ACE2 protein, the functional receptor for SARS coronavirus. A first step in understanding SARS pathogenesis. J Pathol 2004;203:631-7.

89 Perlot T, Penninger JM. ACE2-from the renin-angiotensin system to gut microbiota and malnutrition. Microbes Infect 2013;15:866-73.

90 Imai Y, Kuba K, Rao S, et al. Angiotensin-converting enzyme 2 protects from severe acute lung failure. Nature 2005;436:112-16.

91 Kuba K, Imai Y, Rao $S$, et al. A crucial role of angiotensin converting enzyme 2 (ACE2) in SARS coronavirus-induced lung injury. Nat Med 2005;11:875-9.

92 Zou Z, Yan Y, Shu Y, et al. Angiotensin-converting enzyme 2 protects from lethal avian influenza A H5N1 infections. Nat Commun 2014;5:3594.

93 Huang F, Guo J, Zou Z, et al. Angiotensin II plasma levels are linked to disease severity and predict fatal outcomes in H7N9-infected patients. Nat Commun 2014;5:3595

94 Yang $\mathrm{P}, \mathrm{Gu} \mathrm{H}$, Zhao Z, et al. Angiotensin-converting enzyme 2 (ACE2) mediates influenza H7N9 virus-induced acute lung injury. Sci Rep 2014;4:7027.

95 Marshall RP, Webb S, Bellingan GJ, et al. Angiotensin converting enzyme insertion/deletion polymorphism is associated with susceptibility and outcome in acute respiratory distress syndrome. Am J Respir Crit Care Med 2002;166: $646-50$.

96 Jia HP, Look DC, Shi L, et al. ACE2 Receptor expression and severe acute respiratory syndrome coronavirus infection depend on differentiation of human airway epithelia. J Virol 2005;79:14614-21.

97 Chen W, Sammani S, Mitra S, et al. Critical role for integrin- $\beta 4$ in the attenuation of murine acute lung injury by simvastatin. Am J Physiol Lung Cell Mol Physiol 2012;303:L279-85.

98 Singla S, Jacobson JR. Statins as a novel therapeutic strategy in acute lung injury. Pulm Circ 2012;2:397-406.

99 Jacobson JR, Barnard JW, Grigoryev DN, et al. Simvastatin attenuates vascular leak and inflammation in murine inflammatory lung injury. Am J Physiol Lung Cell Mol Physiol 2005;288:L1026-L32.

100 Müller HC, Hellwig K, Rosseau S, et al. Simvastatin attenuates ventilator-induced lung injury in mice. Crit Care 2010;14:R143.

101 Shyamsundar M, McKeown ST, O'Kane CM, et al. Simvastatin decreases lipopolysaccharide-induced pulmonary inflammation in healthy volunteers. Am J Respir Crit Care Med 2009:179:1107-14.

102 McAuley DF, Laffey JG, O'Kane CM, et al. Simvastatin in the acute respiratory distress syndrome. N Engl J Med 2014;371:1695-703.

103 Truwit JD, Bernard GR, Steingrub J, et al., National Heart, Lung, and Blood Institute ARDS Clinical Trials Network. Rosuvastatin for sepsis-associated acute respiratory distress syndrome. N Engl J Med 2014;370:2191-200.

104 Bellingan G, Maksimow M, Howell DC, et al. The effect of intravenous interferonbeta-1a (FP-1201) on lung CD73 expression and on acute respiratory distress syndrome mortality: an open-label study. Lancet Respir Med 2014;2:98-107.

105 Rizzo AN, Sammani S, Esquinca AE, et al. Imatinib attenuates inflammation and vascular leak in a clinically relevant two-hit model of acute lung injury. Am J Physiol Lung Cell Mol Physiol 2015;309:L1294-304.

106 Druker BJ, Talpaz M, Resta DJ, et al. Efficacy and safety of a specific inhibitor of the BCR-ABL tyrosine kinase in chronic myeloid leukemia. $N$ Engl J Med 2001;344:1031-7.

107 Aman J, Peters MJL, Weenink C, et al. Reversal of Vascular Leak with Imatinib. Am J Respir Crit Care Med 2013;188:1171-3.

108 Carnevale-Schianca F, Gallo S, Rota-Scalabrini D, et al. Complete resolution of life-threatening bleomycin-induced pneumonitis after treatment with imatinib mesylate in a patient with Hodgkin's lymphoma: hope for severe chemotherapy-induced toxicity? J Clin Oncol 2011:29:e691-3.

109 Aman J, van Bezu J, Damanafshan A, et al. Effective treatment of edema and endothelial barrier dysfunction with imatinib. Circulation 2012;126:2728-38.

110 Xing J, Birukova AA. ANP attenuates inflammatory signaling and Rho pathway of lung endothelial permeability induced by LPS and TNFalpha. Microvasc Res 2010;79:56-62. 
111 Birukova AA, Xing J, Fu P, et al. Atrial natriuretic peptide attenuates LPS-induced lung vascular leak: role of PAK1. Am J Physiol Lung Cell Mol Physiol 2010;299: L652-63.

112 Tian Y, Mambetsariev I, Sarich N, et al. Role of microtubules in attenuation of PepG-induced vascular endothelial dysfunction by atrial natriuretic peptide. Biochim Biophys Acta 2015;1852:104-19.

113 Mitaka C, Hirata Y, Nagura T, et al. BEneficial effect of atrial natriuretic peptide on pulmonary gas exchange in patients with acute lung injury. Chest 1998;114:223-8.

114 Itoh T, Obata H, Murakami S, et al. Adrenomedullin ameliorates lipopolysaccharide-induced acute lung injury in rats. Am J Physiol Lung Cell Mol Physiol 2007;293:L446-52.

115 Müller HC, Witzenrath M, Tschernig T, et al. Adrenomedullin attenuates ventilator-induced lung injury in mice. Thorax 2010;65:1077-84.

116 Müller-Redetzky HC, Kummer W, Pfeil U, et al. Intermedin stabilized endothelial barrier function and attenuated ventilator-induced lung injury in mice. PloS ONE 2012:7:1831-41.

117 Létourneau M, Nguyen QT, Harel F, et al. PulmoBind, an adrenomedullin-based molecular lung imaging tool. J Nucl Med 2013;54:1789-96.

118 Meng F, Meliton A, Moldobaeva N, et al. Asef mediates HGF protective effects against LPS-induced lung injury and endothelial barrier dysfunction. Am J Physiol Lung Cell Mol Physiol 2015;308:L452-63.

119 Tian Y, Gawlak G, Shah AS, et al. Hepatocyte growth factor-induced Asef-IQGAP1 complex controls cytoskeletal remodeling and endothelial barrier. J Biol Chem 2015;290:4097-109.

120 Tauseef M, Knezevic N, Chava KR, et al. TLR4 activation of TRPC6-dependent calcium signaling mediates endotoxin-induced lung vascular permeability and inflammation. J Exp Med 2012;2091953-68.

121 Birukova AA, Rios A, Birukov KG. Long-term cyclic stretch controls pulmonary endothelial permeability at translational and post-translational levels. Exp Cell Res 2008;314:3466-77.

122 Iwaki M, Ito S, Morioka M, et al. Mechanical stretch enhances IL-8 production in pulmonary microvascular endothelial cells. Biochem Biophys Res Commun 2009;389:531-6.

123 Birukova AA, Tian Y, Meliton A, et al. Stimulation of Rho signaling by pathologic mechanical stretch is a "second hit" to Rho-independent lung injury induced by IL-6. Am J Physiol Lung Cell Mol Physiol 2012;302:L965-75.

124 Birukova AA, Arce FT, Moldobaeva N, et al. Endothelial permeability is controlled by spatially defined cytoskeletal mechanics: atomic force microscopy force mapping of pulmonary endothelial monolayer. Nanomedicine 2009;5:30-41.

125 Wang $\mathrm{X}$, Bleher $\mathrm{R}$, Brown ME, et al. Nano-biomechanical study of spatio-temporal cytoskeleton rearrangements that determine subcellular mechanical properties and endothelial permeability. Scientific reports 2015;5:11097.

126 Pfeil U, Aslam M, Paddenberg $\mathrm{R}$, et al. Intermedin/adrenomedullin-2 is a hypoxia-induced endothelial peptide that stabilizes pulmonary microvascular permeability. Am JPhysiol Lung Cell Mol Physiol 2009;297:L837-L45.

127 Reutershan J, Vollmer I, Stark S, et al. Adenosine and inflammation: CD39 and CD73 are critical mediators in LPS-induced PMN trafficking into the lungs. FASEB J 2009;23:473-82.

128 Letsiou E, Rizzo AN, Sammani S, et al. Differential and opposing effects of imatinib on LPS- and ventilator-induced lung injury. Am J Physiol Lung Cell Mol Physiol 2015;308:L259-69.

129 Stephens RS, Servinsky LE, Rentsendorj O, et al. Protein kinase G increases antioxidant function in lung microvascular endothelial cells by inhibiting the c-Abl tyrosine kinase. Am J Physiol, Cell Physiol 2014;306:C559-69.

130 Finigan JH, Dudek SM, Singleton PA, et al. Activated protein C mediates novel lung endothelial barrier enhancement: role of sphingosine 1-phosphate receptor transactivation. J Biol Chem 2005;280:17286-93.

131 Lee WL, Downey GP. Neutrophil activation and acute lung injury. Curr Opin Crit Care 2001;7:1-7.

132 Azoulay E, Darmon M, Delclaux C, et al. Deterioration of previous acute lung injury during neutropenia recovery. Crit Care Med 2002;30:781-6.

133 Kangelaris KN, Prakash A, Liu KD, et al. Increased expression of neutrophil-related genes in patients with early sepsis-induced ARDS. Am J Physiol Lung Cell Mol Physiol 2015;308:L1102-13.

134 Doerschuk CM. Leukocyte trafficking in alveoli and airway passages. Respir Res 2000;1:136-40.

135 Doerschuk CM. The role of CD18-mediated adhesion in neutrophil sequestration induced by infusion of activated plasma in rabbits. Am J Respir Cell Mol Biol 1992; 7:140-8.

136 Doyle NA, Bhagwan SD, Meek BB, et al. Neutrophil margination, sequestration, and emigration in the lungs of L-selectin-deficient mice. J Clin Invest 1997;99:526-33.

137 Yin J, Michalick L, Tang C, et al. Role of transient receptor potential vanilloid 4 in neutrophil activation and acute lung injury. Am J Resp Cell Mol 2016;54:370-83.

138 Hamanaka K, Jian MY, Townsley MI, et al. TRPV4 channels augment macrophage activation and ventilator-induced lung injury. Am J Physiol Lung Cell Mol Physiol 2010;299:L353-62.
139 Yin J, Hoffmann J, Kaestle SM, et al. Negative-feedback loop attenuates hydrostatic lung edema via a cGMP-dependent regulation of transient receptor potential vanilloid 4. Circ Res 2008;102:966-74.

140 Lin MT, Jian MY, Taylor MS, et al. Functional coupling of TRPV4, IK, and SK channels contributes to $\mathrm{Ca}(2+)$-dependent endothelial injury in rodent lung. Pulm Circ 2015;5:279-90.

141 Summers $C$, Singh NR, White JF, et al. Pulmonary retention of primed neutrophils: a novel protective host response, which is impaired in the acute respiratory distress syndrome. Thorax 2014;69:623-9.

142 Chollet-Martin S, Montravers P, Gibert C, et al. Subpopulation of hyperresponsive polymorphonuclear neutrophils in patients with adult respiratory distress syndrome. Role of cytokine production. Am Rev Respir Dis 1992:146:990-6.

143 Yadav H, Kor DJ. Platelets in the pathogenesis of acute respiratory distress syndrome. Am J Physiol Lung Cell Mol Physiol 2015;309:L915-23.

144 Zarbock A, Singbartl K, Ley K. Complete reversal of acid-induced acute lung injury by blocking of platelet-neutrophil aggregation. J Clin Invest 2006;116: 3211-19.

145 Yiming MT, Lederer DJ, Sun L, et al. Platelets enhance endothelial adhesiveness in high tidal volume ventilation. Am J Respir Cell Mol Biol 2008:39:569-75.

146 Emin MT, Sun L, Huertas A, et al. Platelets induce endothelial tissue factor expression in a mouse model of acid-induced lung injury. Am J Physiol Lung Cell Mol Physiol 2012;302:L1209-20.

147 Weyrich AS, Zimmerman GA. Platelets in lung biology. Annu Rev Physiol 2013;75:569-91.

148 de Stoppelaar SF, van 't Veer C, Claushuis TA, et al. Thrombocytopenia impairs host defense in gram-negative pneumonia-derived sepsis in mice. Blood 2014;124:3781-90.

149 Caudrillier A, Kessenbrock K, Gilliss BM, et al. Platelets induce neutrophil extracellular traps in transfusion-related acute lung injury. J Clin Invest 2012:122:2661-71.

150 Sayah DM, Mallavia B, Liu F, et al. Neutrophil extracellular traps are pathogenic in primary graft dysfunction after lung transplantation. Am J Respir Crit Care Med 2015;191:455-63.

151 Rafii S, Cao Z, Lis R, et al. Platelet-derived SDF-1 primes the pulmonary capillary vascular niche to drive lung alveolar regeneration. Nat Cell Biol 2015;17: 123-36.

152 Chambers RC, Scotton CJ. Coagulation cascade proteinases in lung injury and fibrosis. Proc Am Thorac Soc 2012;9:96-101.

153 Griffin JH, Zlokovic BV, Mosnier LO. Activated protein C: biased for translation. Blood 2015;125:2898-907.

154 Ye X, Fukudome K, Tsuneyoshi N, et al. The Endothelial Cell Protein C Receptor (EPCR) Functions as a Primary Receptor for Protein C Activation on Endothelial Cells in Arteries, Veins, and Capillaries. Biochem Biophys Res Commun 1999;259:671-7.

155 Christiaans SC, Wagener BM, Esmon CT, et al. Protein C and acute inflammation: a clinical and biological perspective. Am J Physiol Lung Cell Mol Physiol 2013;305 L455-L66.

156 Liu KD, Levitt J, Zhuo $\mathrm{H}$, et al. Randomized clinical trial of activated protein C for the treatment of acute lung injury. Am J Respir Crit Care Med 2008;178: 618-23.

157 Cornet AD, Groeneveld AB, Hofstra JJ, et al. Recombinant human activated protein $C$ in the treatment of acute respiratory distress syndrome: a randomized clinical trial. PLoS ONE 2014;9:e90983.

158 Cornet $A D$, Hofstra JJ, Vlaar AP, et al. Activated protein $C$ attenuates pulmonary coagulopathy in patients with acute respiratory distress syndrome. J Thromb Haemost 2013;11:894-901.

159 Vincent JL, Artigas A, Petersen LC, et al. A multicenter, randomized, double-blind, placebo-controlled, dose-escalation trial assessing safety and efficacy of active site inactivated recombinant factor VIla in subjects with acute lung injury or acute respiratory distress syndrome. Crit Care Med 2009;37:1874-80.

160 José RJ, Williams AE, Mercer PF, et al. Regulation of neutrophilic inflammation by proteinase-activated receptor 1 during bacterial pulmonary infection. J Immunol 2015; 194:6024-34.

161 Rubenfeld GD, Caldwell E, Peabody E, et al. Incidence and outcomes of acute lung injury. N Engl J Med 2005;353:1685-93.

162 Rafat N, Tonshoff B, Bierhaus A, et al. Endothelial progenitor cells in regeneration after acute lung injury: do they play a role? Am J Respir Cell Mol Biol 2013;48:399-405.

163 Hogan BL, Barkauskas CE, Chapman HA, et al. Repair and regeneration of the respiratory system: complexity, plasticity, and mechanisms of lung stem cell function. Cell Stem Cell 2014;15:123-38.

164 Yoder MC. Progenitor cells in the pulmonary circulation. Proc Am Thorac Soc 2011:8:466-70.

165 Burnham EL, Taylor WR, Quyyumi AA, et al. Increased circulating endothelial progenitor cells are associated with survival in acute lung injury. Am J Respir Crit Care Med 2005;172:854-60. 
166 Yamada M, Kubo H, Ishizawa K, et al. Increased circulating endothelial progenitor cells in patients with bacterial pneumonia: evidence that bone marrow derived cells contribute to lung repair. Thorax 2005;60:410-13.

167 Suratt BT, Cool CD, Serls AE, et al. Human pulmonary chimerism after hematopoietic stem cell transplantation. Am J Respir Crit Care Med 2003;168:318-22

168 Asahara T, Murohara T, Sullivan A, et al. Isolation of putative progenitor endothelial cells for angiogenesis. Science 1997:275:964-7.

169 Ormiston ML, Deng Y, Stewart DJ, et al. Innate immunity in the therapeutic actions of endothelial progenitor cells in pulmonary hypertension. Am J Respir Cell Mol Biol 2010;43:546-54

170 Kawasaki T, Nishiwaki T, Sekine A, et al. Vascular Repair by tissue-resident endothelial progenitor cells in endotoxin-induced lung injury. Am J Respir Cell Mol Biol 2015;53:500-12.

171 Ding BS, Nolan DJ, Guo P, et al. Endothelial-derived angiocrine signals induce and sustain regenerative lung alveolarization. Cell 2011;147:539-53.

172 Lee J-H, Bhang Dong $H$, Beede $A$, et al. Lung stem cell differentiation in mice directed by endothelial cells via a BMP4-NFATc1-thrombospondin-1 axis. Cell 2014;156:440-55.
173 Wilson JG, Liu KD, Zhuo $\mathrm{H}$, et al. Mesenchymal stem (stromal) cells for treatment of ARDS: a phase 1 clinical trial. Lancet Respir Med 2015;3:24-32.

174 Rogers AJ, Matthay MA. Applying metabolomics to uncover novel biology in ARDS. Am J Physiol Lung Cell Mol Physiol 2014;306:L957-61.

175 Calfee CS, Janz DR, Bernard GR, et al. Distinct molecular phenotypes of direct versus indirect ards in single and multi-center studies. Chest 2014;147:1539-48.

176 Looney MR, Bhattacharya J. Live imaging of the lung. Annu Rev Physiol 2014;76:431-45.

177 Uhlig S, Yang Y, Waade J, et al. Differential regulation of lung endothelia permeability in vitro and in situ. Cell Physiol Biochem 2014;34:1-19.

178 Huh DD. A human breathing lung-on-a-chip. Ann Am Thorac Soc 2015;12(Suppl 1):S42-4.

179 Huh D, Leslie DC, Matthews BD, et al. A human disease model of drug toxicity-induced pulmonary edema in a lung-on-a-chip microdevice. Sci Trans/ Med 2012;4:159ra47.

180 Esch EW, Bahinski A, Huh D. Organs-on-chips at the frontiers of drug discovery. Nat Rev Drug Discov 2015;14:248-60.

181 Horváth L, Umehara Y, Jud C, et al. Engineering an in vitro air-blood barrier by 3D bioprinting. Sci Reps 2015;5:7974. 